34

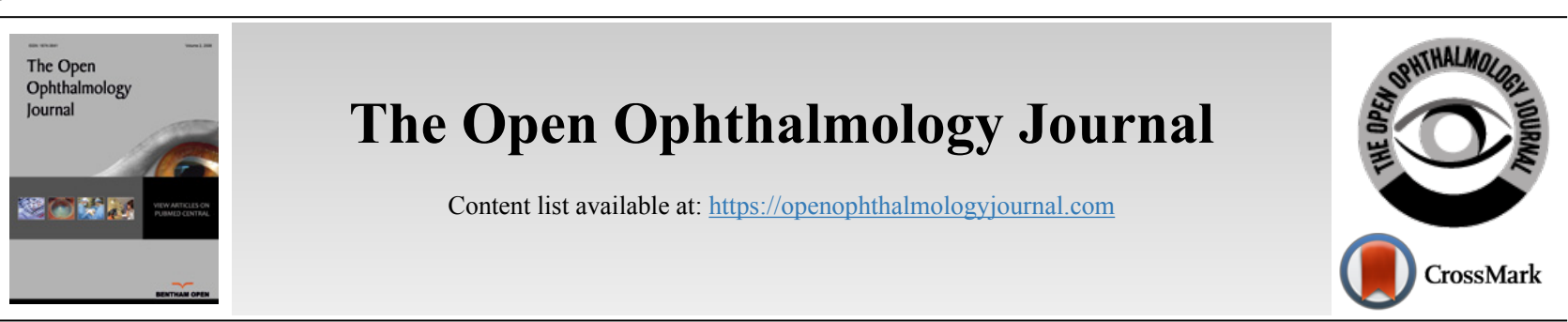

RESEARCH ARTICLE

\title{
Middle East Preferred Practice Patterns for Dry Eye Disease: A Modified Delphi Consensus
}

Ahmed Z. Al-Maskari ${ }^{1}$, Khalid Alarfaj ${ }^{2}$, Mohamed S. Shaheen ${ }^{3}$, Nada Al-Yousuf ${ }^{4}$, Osama Giledi ${ }^{5}$, Saeed Algehedan $^{6}$, Sam Navon ${ }^{7}$ and Sihem Lazreg, ${ }^{8}$

${ }^{1}$ Department of Ophthalmology, Sultan Qaboos University Hospital, Muscat, Oman

${ }^{2}$ Department of Ophthalmology, Imam Abdulrahman Bin Faisal University, Dammam, Saudi Arabia

${ }^{3}$ Department of Ophthalmology, University of Alexandria, Alexandria, Egypt

${ }^{4}$ Department of Ophthalmology, King Abdullah Medical City, Manama, Bahrain

${ }^{5}$ Ophthalmology Department, Moorfields Eye Hospital, Dubai, UAE

${ }^{6}$ Department of Ophthalmology, Specialized Medical Center Hospital, Riyadh, Saudi Arabia

${ }^{7}$ Eye Institute, Cleveland Clinic, Abu Dhabi, UAE

${ }^{8}$ Center of Ophthalmology Lazreg, Blida, Algeria

\section{Abstract: \\ Background:}

Dry Eye Disease (DED) is a common ophthalmic condition resulting from dysfunction in the ocular surface, main lacrimal gland, meibomian glands, or connecting nerves.

Objective:

A group of local experts met to discuss local challenges and establish consensus in DED management across the Middle East.

Methods:

A modified Delphi method was used to reach consensus, comprising two rounds of the survey and a face-to-face meeting. An expert panel of 8 ophthalmologists voted on 23 statements, with consensus reached if $\geq 75 \%$ responded "strongly agree" or "agree" to a statement.

Results:

The expert panel reached consensus on 23 statements relating to the pathophysiology, diagnosis, treatment, and management of DED. Diagnosis begins with recording a detailed patient history and assessing subjective symptoms such as redness, burning, stinging, foreign body sensation, and/or photophobia. Tear Break-up Time (TBUT; $<10 \mathrm{~s}$ ), corneal spots ( $>5$ ), and fluorescein staining are essential for diagnosing DED, assessing disease severity and ocular surface condition, and differentiating between types of DED. Ocular surface lubricants are the mainstay of treatment for DED. Treatment approaches should be categorized by etiology (if known). An improvement in symptoms can be observed objectively via an increase in TBUT, reduction in corneal and conjunctival spots, and restoration of normal tear production, or subjectively via less dependence on ocular surface lubricants, improved vision quality, and symptom amelioration.

Conclusion:

This consensus will serve to provide a framework for clinical decisions relating to the management of DED across the region.

Keywords: Dry eye disease, Middle East, Consensus, Pathophysiology, Diagnosis, Treatment.

\begin{tabular}{|l|l|l|l|}
\hline Article History & Received: August 20, 2020 & Revised: December 15, 2020 & Accepted: January 31, 2021
\end{tabular}

\section{INTRODUCTION}

Dry Eye Disease (DED), or keratoconjunctivitis sicca, is a common ophthalmic condition that results from dysfunction in

\footnotetext{
* Address correspondence to this author at the Center of Ophthalmology Lazreg, 14 Avenue M'kerkeb Benyoucef, Blida, Algeria; Tel: +213770417369;

E-mail: slazbkt@gmail.com
}

the ocular surface, main lacrimal gland, meibomian glands, or the nerves connecting these components, all of which are essential for maintaining the vitality and physiological functions of the ocular surface cells [1]. The principal subjective symptoms of DED include redness, burning, stinging, foreign body sensation, and photophobia [1]. Globally, prevalence rates of DED vary between $5 \%$ and $50 \%$ 
[2]. This variation is attributed to heterogeneous study populations, varied methodological approaches, and geographical differences [1]. In the Middle East, epidemiological data on the prevalence of DED are scarce, but prevalence rates have been reported to be $8.7 \%$ in Iran [3] and 59\% in Jordan [4]. In Saudi Arabia, dry eye symptoms were reported in $32.1 \%$ of an adult population [5].

Quality of life can be significantly impaired in patients with DED. Everyday activities associated with vision that are commonly affected by the disease include reading, computer use, professional work, watching television, and driving [6]. Depression as a result of impaired quality of life has been reported in patients with DED [7]. The economic burden of DED is high, with an estimated direct cost of $\$ 3.84$ billion per year in the United States of America. Once indirect costs are also included, such as loss of work productivity, the overall cost is approximated to be $\$ 55.4$ billion [8].

Local challenges relating to DED in the Middle East include poor patient education concerning DED, lack of a proper general practitioner system, irregular follow-up, high rates of refractive eye surgery, high rates of contact lens wear, and environmental factors. Environmental factors particularly relevant in this region include air-conditioned environments, much time spent indoors, low humidity, fine particulate matter in the air ("PM2.5"), excessive electronic device use, and corrosive salts in the air due to proximity to the sea. In order to improve patient outcomes and provide a framework for clinical decisions relating to the management of DED across the Middle East region, a group of experts met to establish consensus on a number of statements.

\section{MATERIALS AND METHODS}

The Delphi technique was used to gain consensus on recommendations relating to the management of DED from a panel of experts. Here, a modified Delphi process comprised 2 rounds of the survey followed by a face-to-face meeting. In round 1 , experts were asked to complete a survey relating to current practice patterns and clinical experience of DED patient management, including diagnosis and classification, treatment, and clinical practice challenges. Survey questions were designed based on information gathered from the literature. The information gathered formed the basis for the structured consensus recommendation statements created for round 2 .

In round 2 , experts were asked to independently rank a total of 23 consensus recommendation statements across 4 areas using a 4-point scale ("strongly agree," "agree," "disagree," and "strongly disagree") with the option for "neither agree or disagree."

The expert panel consisted of 8 ophthalmologists within the Middle East, each with at least 10 years of clinical practice experience.

The process took place over the course of 3 months. Following the establishment of the expert panel, members were asked to complete the first round of the survey. Following this round, Dr. Osama Giledi drafted initial consensus statements, which were circulated to the other members of the expert panel for voting. Following voting, a face-to-face meeting was held.
The expert panel reviewed the responses to the survey and amended statements as required. Amended statements were then re-circulated for a final round of voting to give the final 23 consensus recommendations. The percentage of consensus was calculated for each statement. The Consensus was reached if $75 \%$ or more of the panel responded "strongly agree" or "agree" to a particular statement.

The consensus was endorsed by the Emirates Society of Ophthalmology.

\section{RESULTS}

\subsection{Pathophysiology}

The expert panel fully agreed (100\% consensus) with the Tear Film and Ocular Surface Society (TFOS) Dry Eye Workshop (DEWS) II definition of DED (Table 1), which is commonly referred to in clinical practice.

Table 1. Statements on pathophysiology.

\begin{tabular}{|c|c|c|}
\hline \multicolumn{2}{|c|}{ Statement } & $\begin{array}{c}\% \\
\text { Consensus }\end{array}$ \\
\hline 1.1 & $\begin{array}{c}\text { Dry eye is a multifactorial disease of the ocular } \\
\text { surface characterized by a loss of homeostasis of } \\
\text { the tear film and accompanied by ocular symptoms, } \\
\text { in which tear film instability and hyperosmolarity, } \\
\text { ocular surface inflammation and damage, and } \\
\text { neurosensory abnormalities play etiological roles } \\
\text { (DEWS II definition) }\end{array}$ & \\
\hline
\end{tabular}

\subsection{Diagnosis}

The expert panel agreed with all statements relating to the diagnosis of DED (Table 2) and confirmation of diagnosis (Table 3). The panel also highlighted that the duration of signs and symptoms must be ascertained for correct diagnosis. Further more, confirmation of diagnosis involves an eyelid

Table 2. Statements on diagnosis.

\begin{tabular}{|c|c|c|}
\hline \multicolumn{2}{|c|}{ Statement } & $\begin{array}{c}\% \\
\text { Consensus }\end{array}$ \\
\hline 2.1 & $\begin{array}{c}\text { Recording a detailed patient history is key to } \\
\text { understanding the etiopathological features of DED } \\
\text { as several conditions are known to mimic DED }\end{array}$ & 100 \\
\hline 2.2 & $\begin{array}{c}\text { The subjective symptoms of dry eye include } \\
\text { redness, burning, stinging, foreign body sensation, } \\
\text { and/or photophobia }\end{array}$ & 100 \\
\hline 2.3 & $\begin{array}{c}\text { Evaluating the eyelids, tear film and meniscus, } \\
\text { cornea, meibomian glands, conjunctiva, lid closure } \\
\text { during blinking, blink rate, and ocular surface are } \\
\text { necessary to confirm a DED diagnosis }\end{array}$ & 100 \\
\hline 2.4 & $\begin{array}{c}\text { Homeostasis markers like tear break-up time (<10 } \\
\text { s), corneal spots ( }>5 \text { ), and fluorescein staining are } \\
\text { essential for the diagnosis of DED, to assess disease } \\
\text { severity and ocular surface condition, and to } \\
\text { differentiate between types of DED }\end{array}$ & 100 \\
\hline 2.5 & $\begin{array}{c}\text { Assessing risk factors of DED is essential to } \\
\text { determining the appropriate treatment strategy }\end{array}$ & 100 \\
\hline 2.6 & $\begin{array}{c}\text { DED is commonly observed in patients with poorly } \\
\text { controlled diabetes, disruptive sleep patterns, post } \\
\text { corneal refractory surgery, extended use of topical } \\
\text { glaucoma treatments, acne rosacea, and systemic } \\
\text { autoimmune diseases }\end{array}$ & 100 \\
\hline
\end{tabular}


examination, specifically looking for blepharitis, chalazion, trichiasis, meibomian gland status, and abnormalities of the lid and lid margin.

DED is associated with a number of conditions, as mentioned in statement 2.6, which the advisors agreed should be managed alongside the management of DED according to
Table 4.

The advisors agreed that assessing risk factors for DED is essential to determining the appropriate treatment strategy. Risk factors particularly relevant in the Gulf region are shown in Fig. (1).

Table 3. Statements on confirming diagnosis.

\begin{tabular}{|c|c|c|}
\hline \multicolumn{2}{|c|}{ Statement } & Patients with two or more of the following will confirm a diagnosis of dry eye: \\
\hline 3.1 & Tear break-up time of $<10 \mathrm{~s}$ & - \\
\hline 3.2 & Tear meniscus height of $<0.5 \mathrm{~mm}$ & 87.5 \\
\hline 3.3 & Tear secretion of $<5 \mathrm{~mm}$ using the Schirmer-I test method & 100 \\
\hline 3.4 & $\begin{array}{r}\text { Due to the large inter- and intra-individual differences observed with the Schirmer-I test, evaluation using this method is difficult } \\
\text { and is, therefore, not recommended to confirm a diagnosis of DED, but can be used as supplementary testing }\end{array}$ & 87.5 \\
\hline 3.5 & $\begin{array}{r}\text { Meibomian gland orifices are obstructed with a cloudy, granular, or solid secretion that can only be expressed by exerting } \\
\text { considerable pressure on the lower lid; or unable to secrete meibum }\end{array}$ & 75 \\
\hline 3.6 & $\begin{array}{c}\text { Damage to the ocular surface can be observed using fluorescein staining of the cornea ( }>5 \text { spots) and conjunctiva ( }>9 \text { spots), and } \\
\text { lid margin ( } \geq 2 \text { mm length and } \geq 25 \% \text { width) }\end{array}$ & 100 \\
\hline
\end{tabular}

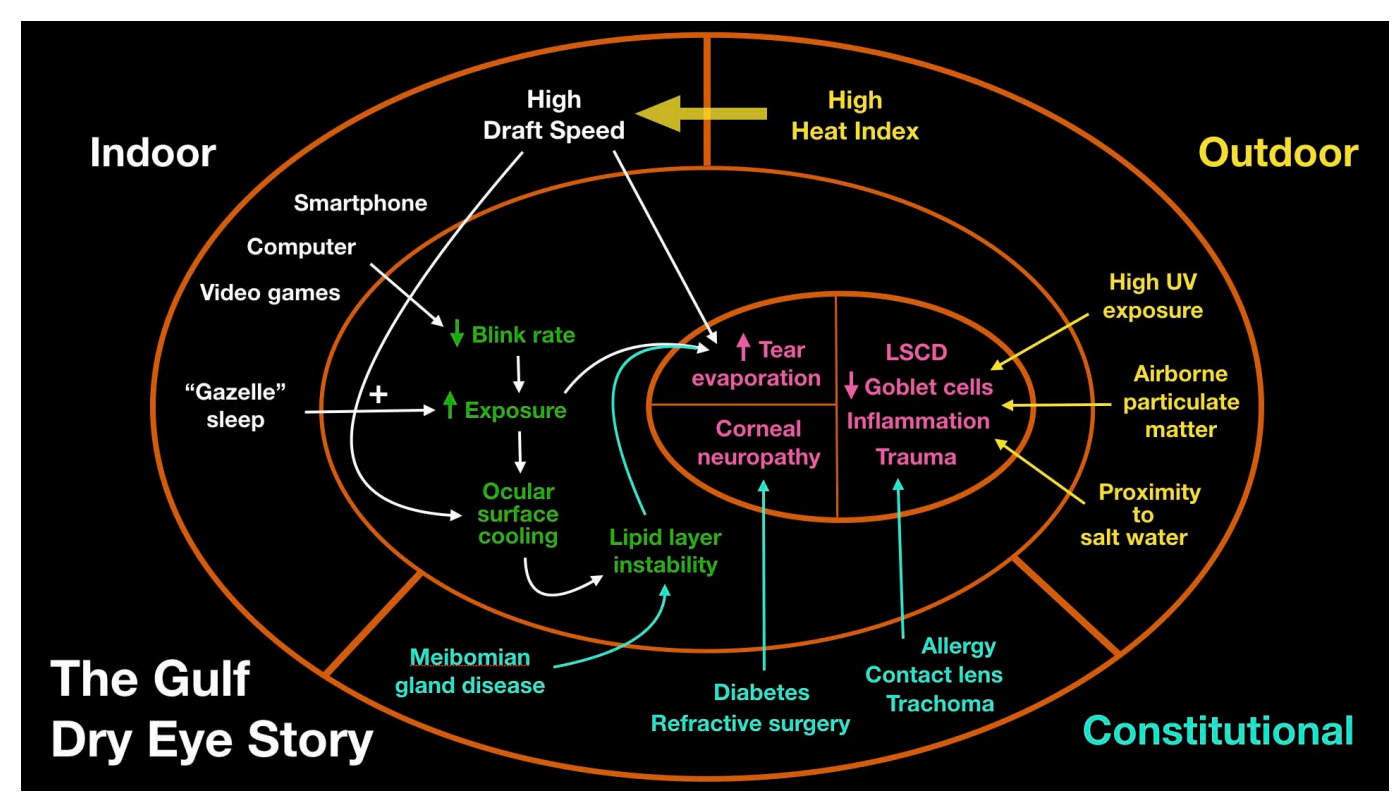

Fig. (1). The Gulf dry eye story. A combination of indoor, outdoor, and constitutional factors leading to DED.

Table 4. Conditions associated with dry eye disease.

\begin{tabular}{|c|c|c|}
\hline Conditions & Management & Advice \\
\hline Glaucoma & $\begin{array}{c}\text { Change to preservative-free drops; consider control of glaucoma with } \\
\text { laser or surgery if DED worsens due to medication }\end{array}$ & Discuss with the glaucoma specialist \\
\hline Diabetes mellitus (DM) & $\begin{array}{c}\text { Improve DM control; more artificial tears; avoid scratch of the corneal } \\
\text { surface during any procedure }\end{array}$ & $\begin{array}{c}\text { DM control } \\
\text { Patients with oxygen or positive airway pressure face masks during } \\
\text { sleep must ensure appropriate fitting of the face mask to avoid oxygen } \\
\text { blowing into the eyes }\end{array}$ \\
\hline $\begin{array}{c}\text { Avoid caffeine at night. Use a blue light filter } \\
\text { in devices at night. Ensure appropriate face } \\
\text { mask fitting. Patients should use thick } \\
\text { lubricants at bedtime, consider taping lids } \\
\text { closed during sleep, and avoid exposure to air- } \\
\text { conditioner airflow and ceiling fans while } \\
\text { asleep }\end{array}$ \\
\hline
\end{tabular}




\begin{tabular}{|c|c|c|}
\hline Conditions & Management & Advice \\
\hline $\begin{array}{l}\text { History of ocular/corneal } \\
\text { refractive surgery }\end{array}$ & Treat dry eye; use cyclosporine to promote recovery; punctal plugs & Tends to improve within 1 year of surgery \\
\hline $\begin{array}{l}\text { Systemic autoimmune } \\
\text { disease }\end{array}$ & $\begin{array}{c}\text { Systemic medication to control; systemic autoimmune disease; punctual } \\
\text { plugs; autologous serum }\end{array}$ & Also monitor with a rheumatologist \\
\hline Acne rosacea & $\begin{array}{l}\text { Treat meibomian gland dysfunction; doxycycline or azithromycin; } \\
\text { eyelid hygiene; steroids }\end{array}$ & See dermatologist \\
\hline
\end{tabular}

It is also important to consider differential diagnoses that may have similar signs and symptoms to DED but do not respond to DED treatment (Table 5). The advisors agreed that the consequences of incorrect diagnosis could be significant and include irreversible vision loss, prolonged patient symptoms and worsening of DED, inefficient treatment and wasted resources, reduced patient satisfaction, and effects on the accuracy of refraction.

Table 5. Differential diagnoses.

\subsection{Treatment}

The expert panel fully agreed with all statements $(100 \%$ consensus) relating to treatment of DED (Table 6).

As agreed in statement 4.3, treatment approaches should be based on etiology, if known. These treatment approaches are shown in Fig. (2).

\begin{tabular}{|c|}
\hline Differential Diagnosis \\
\hline Allergy \\
\hline Contact lens intolerance \\
\hline Conjunctivochalasis \\
\hline Cicatrizing conjunctivitis \\
\hline Superior limbic keratoconjunctivitis \\
\hline Keratoneuralgia \\
\hline Recurrent corneal erosion syndrome \\
\hline Limbal stem cell deficiency \\
\hline Trichiasis and eyelid abnormality / graft versus host disease \\
\hline
\end{tabular}

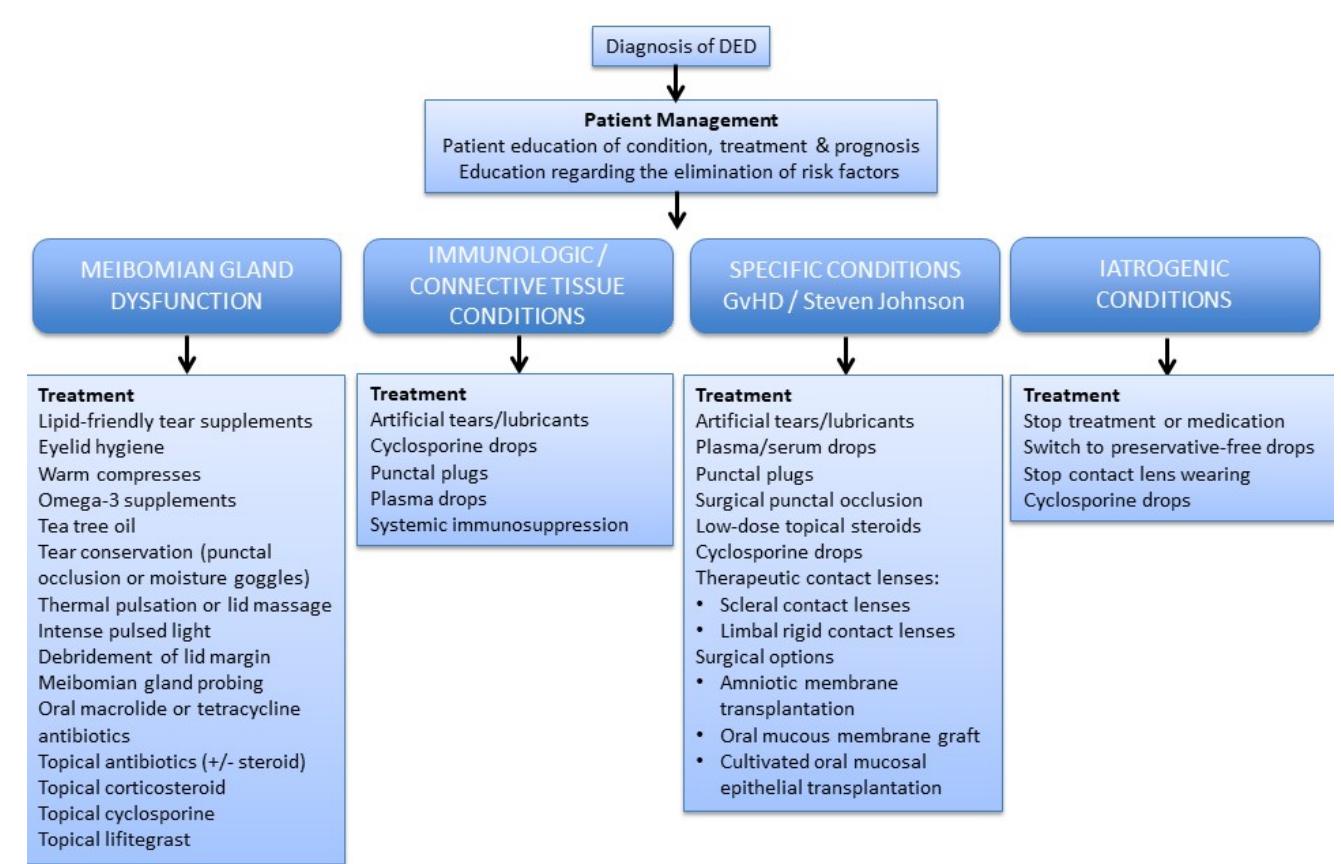

Fig. (2). Algorithm for management of dry eye disease based on etiology (adapted from [9 - 12]). 
Table 6. Statements on treatment.

\begin{tabular}{|c|c|c|}
\hline \multicolumn{2}{|r|}{ Statement } & \multirow{2}{*}{\begin{tabular}{|c|}
$\%$ consensus \\
100 \\
\end{tabular}} \\
\hline 4.1 & The impact of dry eye disease on the quality of life of patients should be taken into consideration while managing DED & \\
\hline 4.2 & The top three factors influencing treatment selection are disease severity, treatment efficacy, and etiology of DED & 100 \\
\hline 4.3 & Treatment approaches should be categorized by etiology (if known) & 100 \\
\hline 4.4 & Ocular surface lubricants are the mainstay of treatment for dry eye disease & 100 \\
\hline 4.5 & Presence of osmoprotectant in the formula would help address a key etiology in DED & 100 \\
\hline 4.6 & $\begin{array}{c}\text { Topical cyclosporine in conjunction with a short course of topical steroids is selected as a treatment for patients with severe } \\
\text { punctate surface staining, meibomian gland dropout, moderate to a severe reduction in tear break-up time, and/or in whom ocular } \\
\text { surface lubricants have not improved the symptoms }\end{array}$ & 100 \\
\hline 4.7 & A short course of topical steroid is advised with close monitoring & 100 \\
\hline 4.8 & Punctal plugs can be selected as a treatment for patients with moderate to severe dry eye with aqueous deficiency & 100 \\
\hline 4.9 & $\begin{array}{l}\text { An objective improvement is considered when there is an increase in the tear break-up time, reduction in the number of corneal } \\
\text { spots and conjunctival spots, and normal tear production }\end{array}$ & 100 \\
\hline 4.10 & $\begin{array}{l}\text { A subjective improvement is considered when there is less dependence on ocular surface lubricants, vision quality, and } \\
\text { amelioration of symptoms }\end{array}$ & 100 \\
\hline
\end{tabular}

\section{DISCUSSION}

\subsection{Pathophysiology}

The expert panel agreed with the DEWS II definition of DED [13]. However, it is acknowledged that clinical practice often differs from published guideline recommendations for a number of reasons, including access to certain medications, factors specific to climate or environment, and patient preference [14]. Nevertheless, the DEWS definition incorporates the most relevant features of the disease and provides the most useful description for guiding clinical practice.

\subsection{Diagnosis}

The expert panel agreed that recording a detailed patient history is key to understanding the etiopathological features of DED. This includes recording subjective symptoms like redness, burning, stinging, foreign body sensation, and photophobia, which are commonly reported symptoms of DED [10]. In order to standardize the recording of such symptoms and their impact, patient questionnaires have been developed, including among others the 5-item Dry Eye Questionnaire (DEQ-5) [15], the Ocular Surface Disease Index (OSDI) [16], and the Impact of Dry Eye on Everyday Life (IDEEL) [17]. The DEQ-5 is shown in the Supplementary File with some additional questions proposed by the expert panel to enhance the physician's understanding of a patient's symptoms.

Furthermore, it is important to document factors that may predispose one to DED. The panel agreed that it is essential to assess risk factors to determine an appropriate treatment strategy for DED. The risk factors with the strongest evidence for an association with DED are older age and female sex [2]. There is some evidence for an association between DED and time spent in low humidity environments, including airconditioned or dusty environments $[18,19]$. Blinking rate or partial blinking are also important risk factors that are commonly monitored in clinical practice [20,21]. Laser in situ keratomileusis eye surgery is widely known to cause symptoms of dry eye 3 to 6 months following surgery, but this is thought to be transient [22]. Furthermore, the prevalence of DED was found to be higher in individuals wearing contact lenses and inoffice workers using computer screens [23]. The use of antihistamines and antidepressants has also been shown to increase the risk of dry eye [24]. Conditions such as autoimmune disease and thyroid disease are also risk factors for the disease $[25,26]$. Finally, menopause hormone treatment and cigarette smoking have also been associated with a greater risk of developing dry eye [24, 27, 28].

The panel agreed that confirmation of diagnosis involves tear film assessment, to include tear break-up time (TBUT), tear meniscus height, and tear secretion assessed using the Schirmer-I test [29]. TBUT is the most commonly used measure of tear film stability, measuring the time between blinking and break in the tear film [29]. A rapid $(<10$ s) TBUT may indicate DED [10]. Fluorescein staining of the cornea, conjunctiva, and the ocular surface is used to visualize the damage to the ocular surface. Disruption in the cells' tight junctions or surface glycocalyx enables damaged cells to take up the stain [30]. Meibomian gland morphology is assessed by meibography (if available), and meibum gland secretion is also assessed to confirm the diagnosis [31]. Finally, blinking and lid closure are analysed [29]. Reduced time between blinks or incomplete blinking are frequently observed in patients with DED [32]. The expert panel agreed that homeostasis markers like TBUT, corneal spots, and fluorescein staining are essential for diagnosis and assessing disease severity and ocular surface condition as well as differentiating between types of DED.

DED is associated with a number of conditions, which the advisors agreed should be managed alongside the management of DED. Glaucoma and DED are commonly found together, although the relationship is not thought to be causative [33]. However, glaucoma medications, which contain preservatives, are thought to cause DED [34]. Poorly controlled diabetes has been associated with DED, with DED showing a significant correlation with proliferative diabetic retinopathy [35]. Sleep disorders are thought to result from distress and pain caused by the symptoms of DED, which results in difficulty in sleeping as well as depression [36]. Additionally, the reverse relationship is observed, with "floppy eyelids," use of continuous positive airways pressure treatment, and ocular surface exposure being associated with sleep apnea and resulting in symptoms of DED 
[37, 38]. Sleeping with eyes partially open, known as lagophthalmos or "gazelle sleep", can also lead to DED [39]. Dry eye is commonly associated with ocular or corneal refractive surgery, which is thought to result from corneal nerve disruption during the procedure [40]. Systemic autoimmune diseases, including Sjögren's syndrome [41], multiple sclerosis (MS) [42], and Graves disease [43], are associated with DED. Sjögren's syndrome involves salivary and lacrimal gland impairment, resulting in dry eyes and mouth [41]. In MS patients, motor control of the eyelids is impaired, leading to reduced tear production [42]. In Graves disease patients, it is thought that meibomian and lacrimal gland dysfunction as well as mechanical eyelid impairment contribute to DED [44]. Acne rosacea is also associated with DED, with meibomian gland dysfunction being prevalent in these patients [45]. Management of patients and their comorbid condition(s) is vital for appropriate management of DED.

\subsection{Treatment}

The expert panel agreed that the impact of DED on the quality of life of patients should be taken into consideration when managing the disease. DED has been shown to have a heavy impact on a person's quality of life. Everyday activities associated with vision that are commonly affected include reading, computer use, professional work, watching television, and driving [6]. DED has also been linked to depression and anxiety, resulting from impaired quality of life [46]. Approximately $13.7 \%$ of patients with DED reported depression, compared with $8.6 \%$ of control subjects without DED [7]. Suicidal ideation has also been reported in patients suffering from the disease [47].

Physicians treating DED advocate for the principle of treating the patient in a comprehensive way, taking into account symptoms as well as pathophysiology [9]. The expert panel agreed that the main three factors influencing treatment decision making are the severity of the disease, treatment efficacy, and disease etiology. Other contributing factors influencing treatment selection include diagnosis of Sjögren's syndrome, use of artificial tears, access to reimbursement, cost of treatment, compliance, socioeconomic status, distance from the treatment center, and patient age. Disease severity is considered by many to be the most significant factor affecting treatment strategy for DED [48]. However, the assessment of disease severity is challenging, resulting from discordance between signs and symptoms and severity as well as types of disease and lack of standardisation in the assessment of severity [49]. Classification of DED etiology serves to guide appropriate diagnosis and treatment of the disease, but overlapping types and subtypes have proved problematic with a potential for misdiagnosis [13]. While the TFOS DEWS II presents aqueous-deficient and evaporative types of DED [50], here we present treatment options based on meibomian gland dysfunction as well as immunogenic/connective tissue, specific or iatrogenic conditions.

The main treatment options for DED include artificial tears, topical cyclosporine, topical steroids, and punctual plugs. Ocular surface lubricants are the mainstay of treatment for DED, as agreed by the expert panel. These lubricants have been shown to be safe and effective for the treatment of DED, with few side effects [51]. Side effects can include vision blurring, foreign body sensation, and discomfort [51]. The panel further agreed that the presence of an osmoprotectant in the formula would help address a key etiology in DED. Osmoprotectants protect cells from damage resulting from osmotic stress by suppressing matrix metalloproteinases (MMPs) and mitogen-activated protein kinases $[52,53]$. The efficacy and safety of hyaluronic acid combined with the osmoprotectant trehalose were assessed in a phase 3 randomized control trial; patient satisfaction was greater than with hyaluronic acid alone [54].

The panel agreed that topical cyclosporine in conjunction with a short course of topical steroids is selected as a treatment for patients with a punctate surface staining, meibomian gland dropout, moderate to severe reduction in TBUT, or for whom ocular surface lubricants have not improved symptoms. Topical cyclosporine reduces ocular inflammation and tear osmolarity, with reduced lymphocyte activation in both Sjögren's syndrome and non-Sjögren's syndrome patients [55]. A randomized control trial demonstrated that $0.5 \%$ cyclosporine A reduced ocular dryness and foreign body sensation after 8 weeks and improved corneal staining and Schirmer test after 4 weeks in moderate to severe cases of DED, compared with vehicle [56]. Meta-analysis of data from 18 randomized controlled trials evaluated the efficacy and safety of cyclosporine $\mathrm{A}$ in the treatment of DED; $100 \%$ of studies showed improvement in patient symptoms, $72 \%$ showed improvement in tear function, and 53\% showed reduced ocular surface damage [57].

Topical steroids, such as methylprednisolone, fluorometholone, loteprednol etabonate, prednisolone, and dexamethasone, have been shown to be effective in the treatment of DED [9]. Methylprednisolone reduced corneal fluorescein scores by 2.6 points, and $57 \%$ of patients had complete symptom relief following 2 weeks of treatment for DED [58]. Patients pre-treated with loteprednol etabonate $(0.5 \%)$ showed improvements in OSDI, Schirmer test, fluorescein staining, and lissamine staining [59]. Dexamethasone, $0.01 \%$ treatment, resulted in a complete or moderate reduction in symptoms in $65 \%$ of patients refractory to conventional treatments [60]. A 28-day course of $0.1 \%$ prednisolone significantly reduced symptoms scores and nerve growth factor expression compared with hyaluronic acid in patients with DED [61]. After 8 weeks, fluorometholone $0.1 \%$ treatment improved corneal fluorescein staining, OSDI, conjunctival goblet cell density, and severity of conjunctival congestion in patients with DED [62]. However, long-term use of topical steroids poses a risk to the patient, with the risk of developing cataracts, high intraocular pressure, and infection $[9,58]$. The expert panel recommended that a short course of topical steroid is advised with close monitoring.

The panel agreed that punctal plugs could be selected as a treatment for patients with moderate to severe DED with aqueous deficiency. Punctal plugs, inserted into the tear ducts, are effective in improving visual acuity in DED patients [63]. However, side effects associated with punctal occlusion include foreign body sensation, epiphora, plug loss, and 
irritation of the eye [64]. Further potential treatment options include biologics and non-steroidal anti-inflammatory drugs.

Patient response to treatment should be monitored closely. The expert panel agreed that an objective improvement is considered when there is an increase in TBUT, reduction in the number of corneal and conjunctival spots, and normal tear production. Furthermore, a subjective improvement is considered when there is less dependence on ocular surface lubricants, improved vision quality, and amelioration of symptoms. Additionally, improvement may be observed using Schirmer's test, OSDI, or MMP-9.

Limitations to this study include the small number of ophthalmologists from which consensus was gained. Nevertheless, the participants in this consensus are key opinion leaders within the ophthalmology field. Therefore their opinions and best practices are of value to the region for the provision of a framework for clinical decisions.

\section{CONCLUSION}

In summary, a group of 8 ophthalmologists within the Middle East, with significant clinical practice experience, have reached a consensus on statements relating to the pathophysiology, diagnosis, treatment, and management of DED using a modified Delphi technique. Such consensus will serve to provide a framework for clinical decisions relating to the management of DED across the region.

\section{LIST OF ABBREVIATIONS}

$\begin{array}{ll}\text { DED } & =\text { Dry Eye Disease } \\ \text { DEWS } & =\text { Dry Eye Workshop } \\ \text { DEQ-5 } & =\text { Dry Eye Questionnaire } \\ \text { DM } & =\text { Diabetes Mellitus } \\ \text { GvHD } & =\text { Graft versus Host Disease } \\ \text { IDEEL } & =\text { Impact of Dry Eye on Everyday Life } \\ \text { MMP } & =\text { Matrix Metalloproteinases } \\ \text { MS } & =\text { Multiple Sclerosis } \\ \text { OSDI } & =\text { Ocular Surface Disease Index } \\ \text { TBUT } & =\text { Tear Break-up Time } \\ \text { TFOS } & =\text { Tear Film and Ocular Surface Society } \\ \text { ETHICS APPROVAL AND CONSENT TO PARTI- } & \end{array}$

Not applicable.

\section{HUMAN AND ANIMAL RIGHTS}

No animals/humans were used for studies that are the basis of this research.

\section{CONSENT FOR PUBLICATION}

Not applicable.

\section{AVAILABILITY OF DATA AND MATERIALS}

The data sets used during the current study can be provided from the corresponding author (S.L), upon reasonable request.

\section{FUNDING}

The consensus meetings held on February 15, 2019, and April 20, 2019, in Dubai, UAE were sponsored by Allergan, Dubai. Sponsorship included travel expenses for all authors. Additionally, SL received an honorarium for presenting as a DEWS ambassador.

\section{CONFLICT OF INTEREST}

SN reports speaker honoraria and PI-related work from Allergan within the past year. SA reports speaker honoraria from Allergan in the past year. MSS reports speaker honoraria from Johnson \& Johnson within the past year. SL reports advisor honoraria from Allergan, Thea, and Santen, as well as speaker honoraria from Thea, Santen, Quantel, and Allergan within the past year. AZAM, NAY, KA, and OG report no conflicts of interest.

\section{ACKNOWLEDGEMENTS}

The authors would like to thank Allergan for providing funding for medical writing assistance. Medical writing support in the development of this manuscript was provided by Abigail Holland of Connect Communications, funded by Allergan, Dubai. Allergan played no role in the collection, analysis, and interpretation of data or the preparation of this manuscript.

\section{SUPPLEMENTARY MATERIAL}

Supplementary material is available on the publishers web site along with the published article.

\section{REFERENCES}

[1] Messmer EM. The pathophysiology, diagnosis, and treatment of dry eye disease. Dtsch Arztebl Int 2015; 112(5): 71-81. [http://dx.doi.org/10.3238/arztebl.2015.0071] [PMID: 25686388]

[2] Stapleton F, Alves M, Bunya VY, et al. TFOS DEWS II Epidemiology Report. Ocul Surf 2017; 15(3): 334-65

[http://dx.doi.org/10.1016/j.jtos.2017.05.003] [PMID: 28736337]

[3] Hashemi H, Khabazkhoob M, Kheirkhah A, et al. Prevalence of dry eye syndrome in an adult population. Clin Exp Ophthalmol 2014; 42(3): $242-8$

[http://dx.doi.org/10.1111/ceo.12183] [PMID: 23927383]

[4] Bakkar MM, Shihadeh WA, Haddad MF, Khader YS. Epidemiology of symptoms of dry eye disease (DED) in Jordan: A cross-sectional non-clinical population-based study. Cont Lens Anterior Eye 2016; 39(3): 197-202.

[http://dx.doi.org/10.1016/j.clae.2016.01.003] [PMID: 26833214]

[5] Alshamrani AA, Almousa AS, Almulhim AA, et al. Prevalence and risk factors of dry eye symptoms in a Saudi Arabian population. Middle East Afr J Ophthalmol 2017; 24(2): 67-73.

[http://dx.doi.org/10.4103/meajo.MEAJO_281_16] [PMID: 28936049]

[6] Miljanović B, Dana R, Sullivan DA, Schaumberg DA. Impact of dry eye syndrome on vision-related quality of life. Am J Ophthalmol 2007; 143(3): 409-15.

[http://dx.doi.org/10.1016/j.ajo.2006.11.060] [PMID: 17317388]

[7] Labbé A, Wang YX, Jie Y, Baudouin C, Jonas JB, Xu L. Dry eye disease, dry eye symptoms and depression: The Beijing Eye Study. $\mathrm{Br}$ J Ophthalmol 2013; 97(11): 1399-403.

[http://dx.doi.org/10.1136/bjophthalmol-2013-303838]

[PMID: 24013959]

[8] Yu J, Asche CV, Fairchild CJ. The economic burden of dry eye disease in the United States: a decision tree analysis. Cornea 2011; 30(4): 379-87.

[http://dx.doi.org/10.1097/ICO.0b013e3181f7f363] [PMID: 21045640]

[9] Jones L, Downie LE, Korb D, et al. TFOS DEWS II management and therapy report. Ocul Surf 2017; 15(3): 575-628.

[http://dx.doi.org/10.1016/j.jtos.2017.05.006] [PMID: 28736343]

[10] Milner MS, Beckman KA, Luchs JI, et al. Dysfunctional tear 
syndrome: dry eye disease and associated tear film disorders - new strategies for diagnosis and treatment. Curr Opin Ophthalmol 2017; 27(Suppl. 1): 3-47

[http://dx.doi.org/10.1097/01.icu.0000512373.81749.b7] [PMID: 28099212]

[11] Tam PM, Young AL, Cheng LL, Lam PT. Topical 0.03\% tacrolimus ointment in the management of ocular surface inflammation in chronic GVHD. Bone Marrow Transplant 2010; 45(5): 957-8.

[http://dx.doi.org/10.1038/bmt.2009.249] [PMID: 19802037]

[12] Sotozono C, Ueta M, Yokoi N. Severe dry eye with combined mechanisms is involved in the ocular sequelae of SJS/TEN at the chronic stage. Invest Ophthalmol Vis Sci 2018; 59(14): DES80-6. [http://dx.doi.org/10.1167/iovs.18-24019] [PMID: 30481810]

[13] Craig JP, Nichols KK, Akpek EK, et al. TFOS DEWS II definition and classification report. Ocul Surf 2017; 15(3): 276-83 [http://dx.doi.org/10.1016/j.jtos.2017.05.008] [PMID: 28736335]

[14] Cabana MD, Rand CS, Powe NR, et al. Why don't physicians follow clinical practice guidelines? A framework for improvement. JAMA 1999; 282(15): 1458-65.

[http://dx.doi.org/10.1001/jama.282.15.1458] [PMID: 10535437]

[15] Chalmers RL, Begley CG, Caffery B. Validation of the 5-Item Dry Eye Questionnaire (DEQ-5): Discrimination across self-assessed severity and aqueous tear deficient dry eye diagnoses. Cont Lens Anterior Eye 2010; 33(2): 55-60.

[http://dx.doi.org/10.1016/j.clae.2009.12.010] [PMID: 20093066]

[16] Schiffman RM, Christianson MD, Jacobsen G, Hirsch JD, Reis BL. Reliability and validity of the ocular surface disease index. Arch Ophthalmol 2000; 118(5): 615-21.

[http://dx.doi.org/10.1001/archopht.118.5.615] [PMID: 10815152]

[17] Abetz L, Rajagopalan K, Mertzanis P, Begley C, Barnes R, Chalmers R. Development and validation of the impact of dry eye on everyday life (IDEEL) questionnaire, a patient-reported outcomes (PRO) measure for the assessment of the burden of dry eye on patients. Health Qual Life Outcomes 2011; 9: 111.

[http://dx.doi.org/10.1186/1477-7525-9-111] [PMID: 22152125]

[18] Iyer JV, Lee SY, Tong L. The dry eye disease activity log study. ScientificWorldJournal 2012; 2012589875

[http://dx.doi.org/10.1100/2012/589875] [PMID: 23193384]

[19] Khurana AK, Choudhary R, Ahluwalia BK, Gupta S. Hospital epidemiology of dry eye. Indian J Ophthalmol 1991; 39(2): 55-8. [PMID: 1916981]

[20] Ousler GW III, Abelson MB, Johnston PR, Rodriguez J, Lane K, Smith LM. Blink patterns and lid-contact times in dry-eye and normal subjects. Clin Ophthalmol 2014; 8: 869-74. [http://dx.doi.org/10.2147/OPTH.S56783] [PMID: 24833893]

[21] Rodriguez JD, Ousler GW III, Johnston PR, Lane K, Abelson MB. Investigation of extended blinks and interblink intervals in subjects with and without dry eye. Clin Ophthalmol 2013; 7: 337-42. [http://dx.doi.org/10.2147/OPTH.S39356] [PMID: 23439943]

[22] Turu L, Alexandrescu C, Stana D, Tudosescu R. Dry eye disease after LASIK. J Med Life 2012; 5(1): 82-4. [PMID: 22574092]

[23] Uchino M, Schaumberg DA, Dogru M, et al. Prevalence of dry eye disease among Japanese visual display terminal users. Ophthalmology 2008; 115(11): 1982-8.

[http://dx.doi.org/10.1016/j.ophtha.2008.06.022] [PMID: 18708259]

[24] Yang WJ, Yang YN, Cao J, et al. Risk factors for dry eye syndrome: a retrospective case-control study. Optom Vis Sci 2015; 92(9): e199-205

[http://dx.doi.org/10.1097/OPX.0000000000000541] [PMID: 25756335]

[25] Nguyen CQ, Peck AB. Unraveling the pathophysiology of Sjogren syndrome-associated dry eye disease. Ocul Surf 2009; 7(1): 11-27. [http://dx.doi.org/10.1016/S1542-0124(12)70289-6] [PMID: 19214349]

[26] Gilbard JP, Farris RL. Ocular surface drying and tear film osmolarity in thyroid eye disease. Acta Ophthalmol (Copenh) 1983; 61(1): 108-16.

[http://dx.doi.org/10.1111/j.1755-3768.1983.tb01401.x] [PMID: 6687972]

[27] Xu L, Zhang W, Zhu XY, Suo T, Fan XQ, Fu Y. Smoking and the risk of dry eye: a Meta-analysis. Int J Ophthalmol 2016; 9(10): 1480-6. [PMID: 27803868]

[28] Alves M, Angerami RN, Rocha EM. Dry eye disease caused by viral infection: review. Arq Bras Oftalmol 2013; 76(2): 129-32. [review]. [http://dx.doi.org/10.1590/S0004-27492013000200016] [PMID: 23828477]
[29] Wolffsohn JS, Arita R, Chalmers R, et al. TFOS DEWS II diagnostic methodology report. Ocul Surf 2017; 15(3): 539-74.

[http://dx.doi.org/10.1016/j.jtos.2017.05.001] [PMID: 28736342]

[30] Bron AJ, Argüeso P, Irkec M, Bright FV. Clinical staining of the ocular surface: mechanisms and interpretations. Prog Retin Eye Res 2015; 44: 36-61.

[http://dx.doi.org/10.1016/j.preteyeres.2014.10.001]

[PMID: 25461622]

[31] Adil MY, Xiao J, Olafsson J, et al. Meibomian gland morphology is a sensitive early indicator of meibomian gland dysfunction. Am J Ophthalmol 2019; 200: 16-25.

[http://dx.doi.org/10.1016/j.ajo.2018.12.006] [PMID: 30578784]

[32] Johnston PR, Rodriguez J, Lane KJ, Ousler G, Abelson MB. The interblink interval in normal and dry eye subjects. Clin Ophthalmol 2013; 7: 253-9.

[http://dx.doi.org/10.2147/OPTH.S39104] [PMID: 23403736]

[33] Leung EW, Medeiros FA, Weinreb RN. Prevalence of ocular surface disease in glaucoma patients. J Glaucoma 2008; 17(5): 350-5. [http://dx.doi.org/10.1097/IJG.0b013e31815c5f4f] [PMID: 18703943]

[34] Gomes JAP, Azar DT, Baudouin C, et al. TFOS DEWS II iatrogenic report. Ocul Surf 2017; 15(3): 511-38. [http://dx.doi.org/10.1016/j.jtos.2017.05.004] [PMID: 28736341]

[35] Najafi L, Malek M, Valojerdi AE, et al. Dry eye and its correlation to diabetes microvascular complications in people with type 2 diabetes mellitus. J Diabetes Complications 2013; 27(5): 459-62.

[http://dx.doi.org/10.1016/j.jdiacomp.2013.04.006] [PMID: 23726741]

[36] Ayaki M, Tsubota K, Kawashima M, Kishimoto T, Mimura M, Negishi K. Sleep disorders are a prevalent and serious comorbidity in dry eye. Invest Ophthalmol Vis Sci 2018; 59(14): DES143-50 [http://dx.doi.org/10.1167/iovs.17-23467] [PMID: 30481819]

[37] Mastrota KM. Impact of floppy eyelid syndrome in ocular surface and dry eye disease. Optom Vis Sci 2008; 85(9): 814-6.

[http://dx.doi.org/10.1097/OPX.0b013e3181852777] [PMID: 18772717]

[38] Hayirci E, Yagci A, Palamar M, Basoglu OK, Veral A. The effect of continuous positive airway pressure treatment for obstructive sleep apnea syndrome on the ocular surface. Cornea 2012; 31(6): 604-8. [http://dx.doi.org/10.1097/ICO.0b013e31824a2040] [PMID: 22410644]

[39] Zeev MS, Miller DD, Latkany R. Diagnosis of dry eye disease and emerging technologies. Clin Ophthalmol 2014; 8: 581-90. [PMID: 24672224]

[40] Denoyer A, Landman E, Trinh L, Faure JF, Auclin F, Baudouin C. Dry eye disease after refractive surgery: comparative outcomes of small incision lenticule extraction versus LASIK. Ophthalmology 2015; 122(4): 669-76.

[http://dx.doi.org/10.1016/j.ophtha.2014.10.004] [PMID: 25458707]

[41] Akpek EK, Klimava A, Thorne JE, Martin D, Lekhanont K, Ostrovsky A. Evaluation of patients with dry eye for presence of underlying Sjögren syndrome. Cornea 2009; 28(5): 493-7. [http://dx.doi.org/10.1097/ICO.0b013e31818d3846] [PMID: 19421051]

[42] Prasad S, Galetta SL. Eye movement abnormalities in multiple sclerosis. Neurol Clin 2010; 28(3): 641-55.

[http://dx.doi.org/10.1016/j.ncl.2010.03.006] [PMID: 20637994]

[43] Gürdal C, Saraç O, Genç I, Kırımlıoğlu H, Takmaz T, Can I. Ocular surface and dry eye in Graves' disease. Curr Eye Res 2011; 36(1): 8-13.

[http://dx.doi.org/10.3109/02713683.2010.526285] [PMID: 21174592]

[44] Kim YS, Kwak AY, Lee SY, Yoon JS, Jang SY. Meibomian gland dysfunction in Graves' orbitopathy. Can J Ophthalmol 2015; 50(4): 278-82.

[http://dx.doi.org/10.1016/j.jcjo.2015.05.012] [PMID: 26257221]

[45] Ghanem VC, Mehra N, Wong S, Mannis MJ. The prevalence of ocular signs in acne rosacea: comparing patients from ophthalmology and dermatology clinics. Cornea 2003; 22(3): 230-3.

[http://dx.doi.org/10.1097/00003226-200304000-00009] [PMID: 12658088]

[46] Li M, Gong L, Chapin WJ, Zhu M. Assessment of vision-related quality of life in dry eye patients. Invest Ophthalmol Vis Sci 2012; 53(9): 5722-7.

[http://dx.doi.org/10.1167/iovs.11-9094] [PMID: 22836767]

[47] Um SB, Yeom H, Kim NH, Kim HC, Lee HK, Suh I. Association between dry eye symptoms and suicidal ideation in a Korean adult population. PLoS One 2018; 13(6)e0199131

[http://dx.doi.org/10.1371/journal.pone.0199131] [PMID: 29924835]

[48] Behrens A, Doyle JJ, Stern L, et al. Dysfunctional tear syndrome: A 
Delphi approach to treatment recommendations. Cornea 2006; 25(8): 900-7.

[http://dx.doi.org/10.1097/01.ico.0000214802.40313.fa] [PMID: 17102664]

[49] Baudouin C, Aragona P, Van Setten G, et al. Diagnosing the severity of dry eye: A clear and practical algorithm. Br J Ophthalmol 2014; 98(9): 1168-76.

[http://dx.doi.org/10.1136/bjophthalmol-2013-304619] [PMID: 24627252]

[50] Bron AJ, de Paiva CS, Chauhan SK, et al. TFOS DEWS II pathophysiology report. Ocul Surf 2017; 15(3): 438-510 [http://dx.doi.org/10.1016/j.jtos.2017.05.011] [PMID: 28736340]

[51] Pucker AD, Ng SM, Nichols JJ. Over the counter (OTC) artificial tear drops for dry eye syndrome. Cochrane Database Syst Rev 2016; 2CD009729

[http://dx.doi.org/10.1002/14651858.CD009729.pub2] [PMID: 26905373]

[52] Deng R, Su Z, Hua X, Zhang Z, Li DQ, Pflugfelder SC. Osmoprotectants suppress the production and activity of matrix metalloproteinases induced by hyperosmolarity in primary human corneal epithelial cells. Mol Vis 2014; 20: 1243-52. [PMID: 25352733]

[53] Corrales RM, Luo L, Chang EY, Pflugfelder SC. Effects of osmoprotectants on hyperosmolar stress in cultured human corneal epithelial cells. Cornea 2008; 27(5): 574-9.

[http://dx.doi.org/10.1097/ICO.0b013e318165b19e]

[PMID: 18520508]

[54] Chiambaretta F, Doan S, Labetoulle M, et al. A randomized, controlled study of the efficacy and safety of a new eyedrop formulation for moderate to severe dry eye syndrome. Eur $\mathrm{J}$ Ophthalmol 2017; 27(1): 1-9.

[http://dx.doi.org/10.5301/ejo.5000836] [PMID: 27445067]

[55] Kunert KS, Tisdale AS, Stern ME, Smith JA, Gipson IK. Analysis of topical cyclosporine treatment of patients with dry eye syndrome: effect on conjunctival lymphocytes. Arch Ophthalmol 2000; 118(11): 1489-96.

[http://dx.doi.org/10.1001/archopht.118.11.1489] [PMID: 11074805]

[56] Chen M, Gong L, Sun X, et al. A comparison of cyclosporine $0.05 \%$ ophthalmic emulsion versus vehicle in Chinese patients with moderate to severe dry eye disease: an eight-week, multicenter, randomized, double-blind, parallel-group trial. J Ocul Pharmacol Ther 2010; 26(4):
361-6.

[http://dx.doi.org/10.1089/jop.2009.0145] [PMID: 20698799]

[57] Sacchetti M, Mantelli F, Lambiase A, Mastropasqua A, Merlo D, Bonini S. Systematic review of randomised clinical trials on topical ciclosporin A for the treatment of dry eye disease. Br J Ophthalmol 2014; 98(8): 1016-22.

[http://dx.doi.org/10.1136/bjophthalmol-2013-304072] [PMID: 24344232]

[58] Marsh P, Pflugfelder SC. Topical nonpreserved methylprednisolone therapy for keratoconjunctivitis sicca in Sjögren syndrome. Ophthalmology 1999; 106(4): 811-6.

[http://dx.doi.org/10.1016/S0161-6420(99)90171-9] [PMID: 10201607]

[59] Sheppard JD, Donnenfeld ED, Holland EJ, et al. Effect of loteprednol etabonate $0.5 \%$ on initiation of dry eye treatment with topical cyclosporine $0.05 \%$. Eye Contact Lens 2014; 40(5): 289-96.

[http://dx.doi.org/10.1097/ICL.0000000000000049] 25083776]

[60] Jonisch J, Steiner A, Udell IJ. Preservative-free low-dose dexamethasone for the treatment of chronic ocular surface disease refractory to standard therapy. Cornea 2010; 29(7): 723-6.

[http://dx.doi.org/10.1097/ICO.0b013e3181b765a6] 20489601]

[61] Lee HK, Ryu IH, Seo KY, Hong S, Kim HC, Kim EK. Topical 0.1\% prednisolone lowers nerve growth factor expression in keratoconjunctivitis sicca patients. Ophthalmology 2006; 113(2): 198-205.

[http://dx.doi.org/10.1016/j.ophtha.2005.09.033] [PMID: 16360211]

[62] Lin T, Gong L. Topical fluorometholone treatment for ocular dryness in patients with Sjögren syndrome: A randomized clinical trial in China. Medicine (Baltimore) 2015; 94(7)e551

[http://dx.doi.org/10.1097/MD.0000000000000551]

[PMID: 25700323]

[63] Goto E, Yagi Y, Kaido M, Matsumoto Y, Konomi K, Tsubota K. Improved functional visual acuity after punctal occlusion in dry eye patients. Am J Ophthalmol 2003; 135(5): 704-5.

[http://dx.doi.org/10.1016/S0002-9394(02)02147-5]

[PMID: 12719079]

[64] Ervin AM, Wojciechowski R, Schein O. Punctal occlusion for dry eye syndrome. Cochrane Database Syst Rev 2010; (9): CD006775 [PMID: 20824852]

\section{C) 2021 Al-Maskari et al.}

This is an open access article distributed under the terms of the Creative Commons Attribution 4.0 International Public License (CC-BY 4.0), a copy of which is available at: (https://creativecommons.org/licenses/by/4.0/legalcode). This license permits unrestricted use, distribution, and reproduction in any medium, provided the original author and source are credited. 